\title{
Perinatal dengue infection due to vertical transmission
}

\author{
S K Lokuarachchi ${ }^{1}$ ， J V G M Jayasekara ${ }^{2}$ \\ Sri Lanka Journal of Child Health, 2007; 36: 146-7
}

(Key words: perinatal, dengue, vertical transmission)

\section{Introduction}

Dengue is a mosquito born flavivirus infection, endemic in Southeast Asia ${ }^{1}$. Vertical transmission of dengue infection is rare $^{2}$ and there are only a few reports of vertical dengue virus transmission, occurring at or near time of delivery. We report a case of dengue fever in a neonate, born to a mother who had dengue fever during last week of pregnancy.

\section{Case report}

A 24 hour old term baby of $2.4 \mathrm{~kg}$ was transferred to our unit, from Teaching Hospital Mahamodara. The purpose of transfer was to facilitate breast feeding, as the mother was transferred to a medical ward at Teaching hospital Karapitiya for a febrile illness of five days duration.

The antenatal period had been unremarkable except for the febrile illness in the last week of pregnancy. Delivery was uneventful and the baby was well at birth. A few hours after admission the baby was noted to have fever. There were no positive physical signs. He was treated for a presumptive diagnosis of neonatal septicaemia, with parenteral antibiotics after obtaining samples for blood and urine cultures.

Initial investigations revealed a haemoglobin $(\mathrm{Hb})$ level of $16.9 \mathrm{~g} \%$, a white blood cell (WBC) count of $13 \times 10^{9} / \mathrm{L}$ ( N 53\%, L $42 \%$, E $05 \%$ ), a platelet count of $206 \times 10^{9} / \mathrm{L}$, and a packed cell volume (PCV) of 48 . The fever continued despite antibiotics, but there was no clinical deterioration.

Blood and urine cultures were sterile. C-reactive protein was $<6 \mathrm{mg} / \mathrm{L}$. At age of 4 days theplatelet count was $119 \times 10^{9} / \mathrm{L}$ and $\mathrm{PCV}$ was 52 . Blood picture showed normocytic normochromic red blood cells (RBCs), with leucopenia and thrombocytopenia suggestive of dengue fever. On the sixth day baby was flushed and was noted to have a petechial rash but was haemodynamically stable. Platelet count fluctuated between $20 \times 10^{9} / \mathrm{L}$ and $40 \times 10^{9} / \mathrm{L}$ until Day 7 and steadily increased after that. Stools for occult blood was negative. SGOT and SGPT were 51 \& $30 \mathrm{IU} / \mathrm{L}$ respectively. Serology for dengue virus was positive for both IgG and IgM. He was treated with intravenous fluids for 24 hours and subsequently

${ }^{1}$ Consultant Paediatrician, ${ }^{2}$ Senior House Officer in Paediatrics, Teaching Hospital, Karapitiya, Galle.

(Received 17 October 2006. Accepted on 4 November 2006) with expressed breast milk. He stayed in the ward till his mother was well and was discharged on Day 14. A repeat test for serology on Day 14 too had an antibody titre suggestive of recent Dengue virus type 2 infection.

Mother's febrile illness was associated with thrombocytopenia and was diagnosed as dengue fever. She too had both IgG and IgM for dengue virus in her serum.

\section{Discussion}

Dengue virus infection causes a wide spectrum of disease. It has a predilection for the paediatric age group with a modal age group of 4-6 years ${ }^{3}$. Even children younger than one year can develop severe illness with the first infection if they have placentally transmitted enhancing antibodies ${ }^{3}$.

Dengue / Dengue haemorrhagic fever in the neonate is uncommon. Vertical transmission of dengue virus infection can occur if the mother develops dengue fever during pregnancy, especially close to delivery ${ }^{1}$. Neonate can develop a febrile illness with thrombocytopenia and even dengue shock syndrome ${ }^{1,3}$. Both IgG and IgM antibodies are present in the baby's serum ${ }^{1,3}$. Clinically the illness may mimic neonatal septicaemia and the diagnosis of dengue may be easily overlooked. Though rare, vertical transmission of dengue virus infection can be a potential cause of neonatal death ${ }^{2,3,4}$.

\section{References}

1. Phupong V. Dengue fever in pregnancy: a case report. BMC Pregnancy and Childbirth 2001; 1:7.

2. Chye JK, Lim CT, Ng KB, Lim JM, George R, Lam SK: Vertical transmission of dengue. Clin.Infect.Dis. 1997; 25: 1374 - 7.

3. Choudhry SP, Gopal RK, Krishan J. Dengue shock syndrome in newborn - a case series. Indian Paediatrics 2004, 41: 397 - 9.

4. Kerdpanich A, Watanaveeradej V, Samakoses R, Chumnanvanakij S, Chulyamitporn T, Sumeksri $\mathrm{P}$ et al. Perinatal dengue infection. Southeast Asian J Trop Med Public Health 2001, 32: 488 
